\title{
A Correlation between Wnt/Beta-catenin Signaling and the Rate of Dentin Secretion
}

Yuan Zhao DDS, PhD1,2, Xue Yuan $\mathrm{PhD}^{2}$, Teresita Bellido $\mathrm{PhD}^{3}$, Jill A. Helms DDS, $\mathrm{PhD}^{1,2}$.

1. Department of Cariology and Endodontology, School of Dentistry, Lanzhou University, Lanzhou, China

2. Division of Plastic and Reconstructive Surgery, Department of Surgery, Stanford School of Medicine, Stanford, California

3. Departments of Anatomy and Cell Biology and Medicine, Division of Endocrinology, Indiana University School of Medicine and Roudebush Veterans Administration Medical Center, Indianapolis, Indiana

This is the author's manuscript of the article published in final edited form as: 


\section{ABSTRACT}

\section{INTRODUCTION}

Odontoblasts produce dentin throughout life and in response to trauma. The purpose of this study was to identify the roles of endogenous Wnt signaling in regulating the rate of dentin accumulation.

\section{METHODS}

Histology, immunohistochemistry, vital dye labeling, and histomorphometric assays were used to quantify the rate of dentin accumulation as a function of age. Two strains of Wnt reporter mice were used to identify and follow the distribution and number of Wntresponsive odontoblasts as a function of age. To show a causal relationship between dentin secretion and Wnt signaling, dentin accumulation was monitored in a strain of mice in which Wnt signaling was aberrantly elevated.

\section{RESULTS}

Dentin deposition occurs throughout life, but the rate of accumulation slows with age. This decline in dentin secretion correlates with a decrease in endogenous Wnt signaling. In a genetically modified strain of mice, instead of tubular dentin, aberrantly elevated Wnt signaling resulted in accumulation of reparative dentin or osteodentin secreted from predontoblasts.

\section{CONCLUSIONS}

Wnt signaling regulates dentin secretion by odontoblasts, and the formation of reparative or osteodentin is the direct consequence of elevated Wnt signaling. These preclinical data have therapeutic implications for the development of a biologically based pulp capping medicant.

KEY WORDS: Aging, odontoblasts, pulp, Wnt signal 


\section{SIGNIFICANCE}

Our study revealed Wnt signaling regulates dentin secretion by odontoblasts, which has therapeutic implications for the development of a biologically based pulp capping medicant.

Bone turnover is maintained by osteoclasts that resorb bone matrix and osteoblasts that deposit new matrix. With aging, the balance between osteoblast and osteoclast function is lost, and the result is osteoporosis, a low bone mass disease $1, \underline{2}$. On the other hand, the dental pulp only houses dentin-producing odontoblasts; consequently, dentin accumulates with age 3 .

In response to activities of daily living including exercise that can cause microcracks, osteoclasts resorb mineralized matrix, and osteoblasts deposit new osteoid. This remodeling activity restores the structural integrity of the skeleton. The dental pulp is also capable of mounting a response to subacute trauma (eg, extreme temperature changes or acid production by bacteria), but this is distinctive from bone because there is no remodeling activity. Instead, odontoblasts can only increase their rate of dentin secretion and, in doing so, create a thicker protective barrier between the insult and the pulp 4 . In acute trauma, other cells in the pulp (eg, preodontoblasts) can be recruited to rapidly secrete a mineralized matrix that protects the pulp. This mineralized tissue does not have a tubular structure because the cells producing it lack processes $\underline{5}, \underline{6}$ and is called osteoidlike dentin or osteodentin?

A key regulator of the balance between osteoblast and osteoclast function is the Wnt pathway $\underline{8}, \underline{9}, \underline{10}$. Wht signals operate at multiple levels in the programs of osteoblastogenesis and osteoclastogenesis, but, in general, the effects of this pathway can be summarized as having a pro-osteogenic effect 11 . For example, the genetic gain in Wnt function mutations causes high bone mass conditions $\underline{12}, \underline{13}$, whereas the loss of Wnt function leads to low bone mass diseases including osteoporosis $\frac{14}{14}$. Studies have shown that the Wnt pathway is also operational in the dental pulp $\underline{15}, \underline{16}, \underline{17}, \underline{18}, \underline{19}, \underline{20}$.

In the present study, we sought to better understand the role of Wnt signaling in agerelated changes to the pulp, specifically how these changes might contribute to the ability 
of the pulp to respond to subacute traumas resulting from the activities of daily living. We used 4 transgenic mouse strains: in the Axin2 $2^{L a c Z /+}$ strain of mice, the LacZ gene is under control of the promoter for the Wnt-dependent target gene Axin221; consequently, Wntresponsive cells can be identified by visualization of X-gal staining $\frac{15}{}$. In the Axin2CreERT2/+; R26RmTmG/+ strain of mice, the Cre gene is under control of the Axin2 promoter; when presented with tamoxifen, cells expressing Cre undergo a recombination event and then become permanently labeled with green fluorescent protein (GFP) $\underline{16}, \underline{19}$. Thus, Wnt-responsive cells and all their progeny express GFP $\underline{15}$. Finally, in

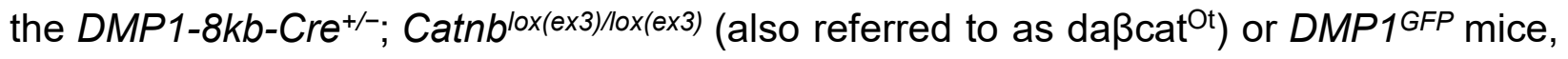
the Cre or GFP gene is under control of the DMP1 promoter; DMP1 is expressed in odontoblasts $\underline{22}$. Therefore, in daßcat ${ }^{\mathrm{Ot}}$ mice, beta-catenin is stabilized, leading to elevated Wnt signaling in DMP1-expressing cells.

Collectively, analyses of tissues from these mice showed that

1. odontoblasts are sensitive to an endogenous Wnt signal;

2. endogenous Wnt signaling in the pulp decreases with age along with the rate of dentin secretion; and

3. genetically amplifying Wnt signaling in the pulp leads to a massive and rapid accumulation of dentin that, because of its rate of accrual, resembles osteodentin.

\section{MATERIALS AND METHODS}

\section{ANIMALS}

Experimental procedures were approved by the Stanford Committee on Animal Research (\#13146) and the Institutional Animal Care and Use Committee of Indiana University School of Medicine. Four strains of transgenic mice were used: Axin2 $2^{\mathrm{LacZ} /+}$, Axin2 ${ }^{\mathrm{CreERT2/+}} ; \mathrm{R}^{26 R^{\mathrm{mTm} /+}, \text { DMP1-8kb- }}$

$\mathrm{Cre}^{+-} ;$Catnb $^{\text {lox(ex3)//ox(ex3) }}\left(\mathrm{da}^{\mathrm{B}} \mathrm{cat}^{\mathrm{Ot}}\right)$, and DMP1GFP. For detailed information on the individual strains as well as breeding, please see the Supplemental Materials and Methods (available online at www.jendodon.com). 


\section{VITAL DYE LABELING AND QUANTIFICATION OF MINERAL APPOSITION RATE}

Vital dye labeling was previously described $\underline{23}$. Mice were intraperitoneally injected with 20 $\mathrm{mg} / \mathrm{kg}$ calcein (Sigma-Aldrich, St Louis, MO) and $30 \mathrm{mg} / \mathrm{kg}$ alizarin red (Sigma-Aldrich) with a 10-day interval. Two days after alizarin red injection, the mice were sacrificed and harvested. Samples were fixed in 4\% paraformaldehyde overnight, dehydrated with $30 \%$ sucrose overnight, and then processed for hard tissue embedding and sectioning using Kawamoto's method $\underline{24}$. Mineral apposition rates were calculated by measuring the distance between the calcein-labeled bone (green line) and the alizarin red-labeled bone (red line); this measurement was made at 8 distinct, randomly chosen sites around the maxillary first molars in 3 separate mice. The mineral apposition rate was then calculated as the distance in micrometers per interval of time between when the labels were injected.

\section{SAMPLE PREPARATION, PROCESSING, HISTOLOGY, X-GAL STAINING, AND IMMUNOHISTOCHEMISTRY ASSAYS}

Maxillae were harvested, fixed, sectioned at a thickness of $8 \mu \mathrm{m}$, and processed using established procedures $\frac{18}{}$. Aniline blue and Movat pentachrome staining were performed as described previously $\underline{18}, \underline{25}$. For aniline blue staining, sections were submerged in $1 \%$ aniline blue (B8563, Sigma-Aldrich) for 3 minutes until a dark blue color developed. Slides were then washed in 1\% acetic acid (A38-212; Fisher Scientific, Waltham, MA) for 5 minutes and repeated twice until appropriately discolored. The Movat pentachrome method uses alcian blue (A3157, Sigma-Aldrich), sodium thiosulfate (14518, Alfa Aesar), crocein scarlet (210757, Sigma-Aldrich) acid fuchsin (F8129, Sigma-Aldrich), phosphotungstic acid (P4006, Sigma-Aldrich), acetic acid, and alcoholic saffron (3801, Sigma-Aldrich). Movat pentachrome staining results in nuclei that are black; collagen and reticulin that are yellow; glycosaminoglycans that are light blue; and muscle, cytoplasm, and keratin that are red르. Dentin and alveolar bone were stained green/yellow, whereas the periodontal ligament and dental pulp stain red.

To detect beta-galactosidase activity, X-gal staining was performed (Supplemental Materials and Methods is available online at www.jendodon.com). Immunostaining was performed using standard procedures $\underline{25}$. For the information of primary and secondary 
antibodies, please see the Supplemental Materials and Methods (available online at www.jendodon.com).

\section{STATISTICAL ANALYSES}

All data were presented as mean \pm standard deviation of each group. One-way analysis of variance was used to quantify differences using Prism 7 (GraphPad Software, San Diego, CA). A $P$ value $\leq .05$ was considered significant.

\section{RESULTS}

\section{DENTIN DEPOSITION RATE DECLINES WITH AGE}

Similar to humans, we found that mice exhibited an accumulation of dentin throughout life, and, as a consequence, the volume of the pulp cavity was gradually reduced (Fig. 1 $A-C$, quantified in Fig. 1D). This increase in dentin volume occurred even as the rate of dentin accumulation slowed in older mice (Fig. 1D); for example, the average rate of dentin deposition in 1-month-old mice was between 2.1 8.4 $\mu \mathrm{m} / \mathrm{d}$ (Fig. 1E), whereas in 6-month-old mice, the rate of deposition was below the limit of resolution (Fig. 1F).

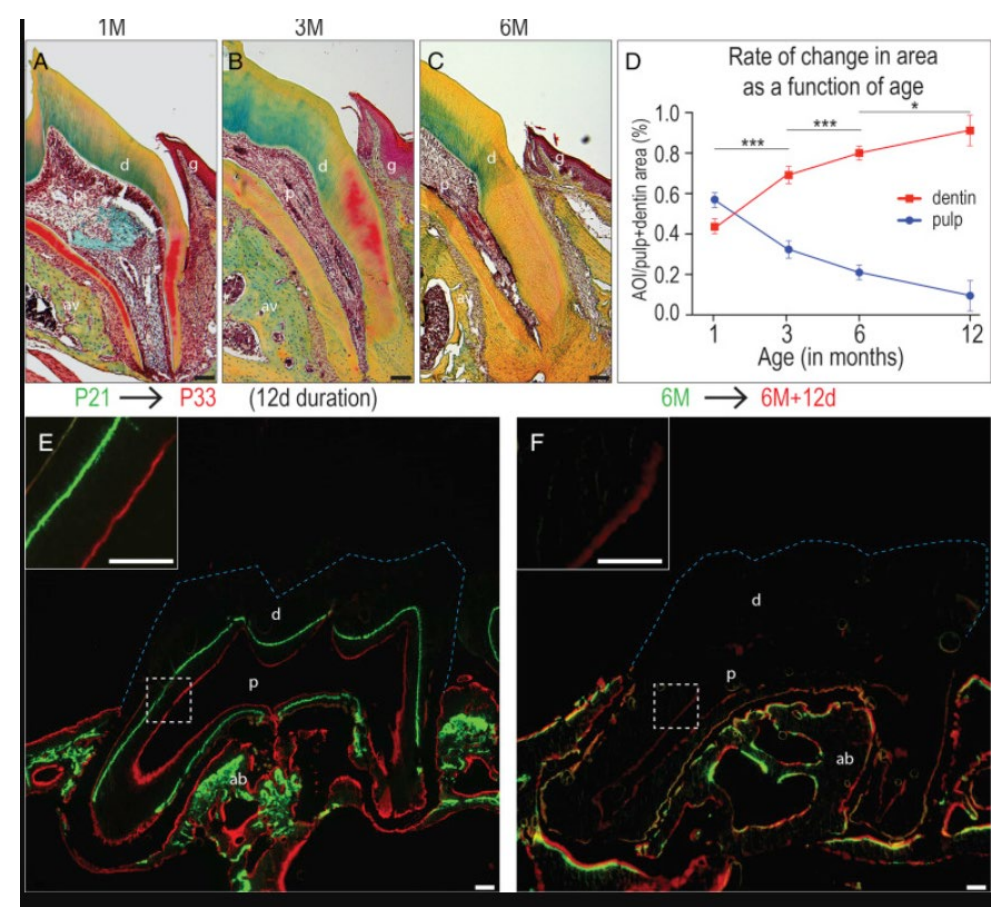

Figure 1. The dentin deposition rate declines with age. Representative Movat pentachrome-stained maxillary molar sections showing the dentin thickness and pulp 
volume in the $(A)$ 1-month-old $(1 \mathrm{M}),(B)$ 3-month-old (3M), and $(C)$ 6-month-old $(6 \mathrm{M})$ groups. In Movat pentachrome, dentin and alveolar bone stain green to yellow, and the periodontal ligament and dental pulp stain red. $(D)$ Quantification of the pulp area and dentin area over the total pulp + dentin area from $1 \mathrm{M}, 3 \mathrm{M}, 6 \mathrm{M}$, and 12M mice $(n=3$ for each group). Vital dye labeling showing the new dentin formation in mice around $(E) 1$ month and $(F) 6$ months old in a 10-day interval. Calcein (green) was first injected, alizarin red (red) was injected 10 days later, and mice were harvested 2 days after the last injection. The blue dotted lines indicate the crown. $d$, dentin; p, pulp; ab, alveolar bone; g, gingiva. Scale bars $=100 \mu \mathrm{m}$. Data are expressed as the mean \pm standard deviation. ${ }^{*} P<.05 ;{ }^{* * *} P<.0001$.

\section{THE DECLINE IN DENTIN DEPOSITION IS PARALLELED BY REDUCED WNT RESPONSIVENESS}

Does Wnt signaling regulate the rate of dentin secretion? In Axin2 ${ }^{L a c Z /+}$ reporter mice, cells that are responsive to an endogenous Wnt signal can be identified by their $\mathrm{X}$ gal $^{+v e}$ status. In 1-month-old mice, abundant X-gal ${ }^{+v e}$ cells lined the dentin/pulp interface (Fig. 2A). In 3-month-old mice, a single layer of $\mathrm{X}$-gal ${ }^{+v e}$ Wnt-responsive odontoblasts was evident (Fig. $2 B$ ). In 6-month-old mice, only a small portion of odontoblasts remained $\mathrm{X}$-gal ${ }^{\text {+ve }}$ (Fig. 2C). Thus, within the pulp, there was a significant decline in the number of $X-g a l^{\text {tve }}$ cells as a function of age (Fig. 2D). 


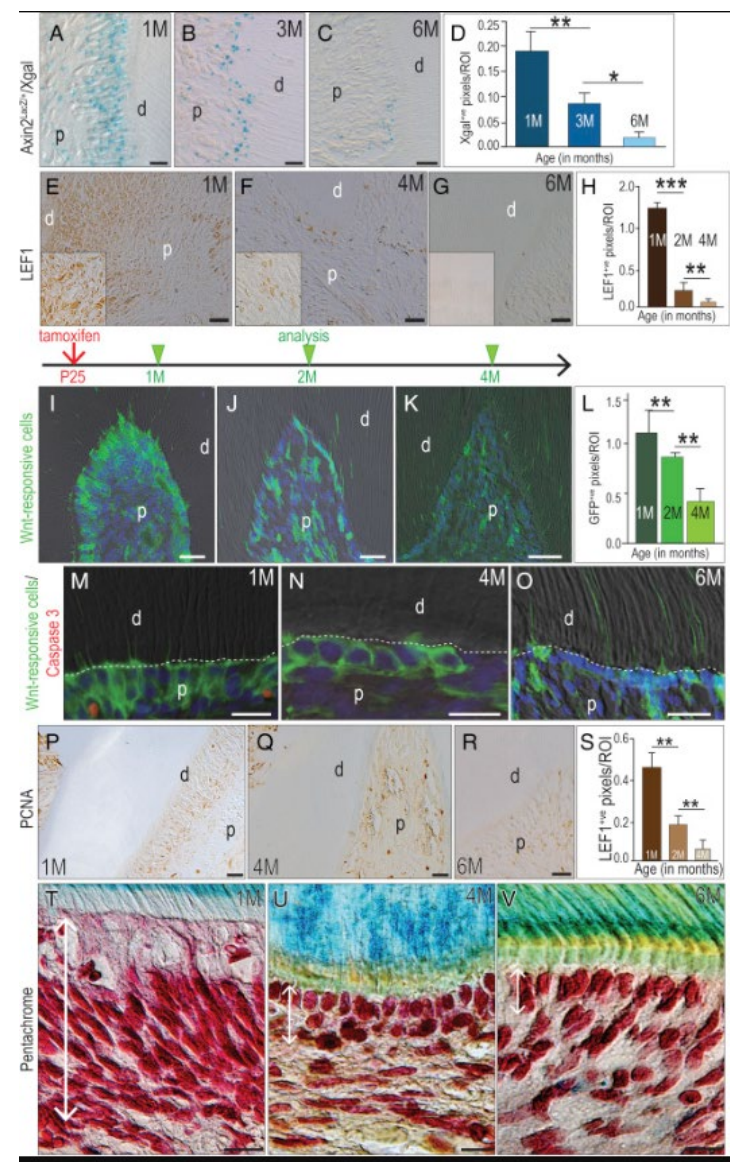

Figure 2. The decline in dentin deposition is paralleled by a decline in the population of Wnt-responsive odontoblasts. X-gal ${ }^{+v e}$, Wnt-responsive cells in the maxillary first molars at the age of $(A) 1$ month (1M), (B) 3 months (3M), and (C) 6 months (6M). (D) Quantification of X-gal ${ }^{+v e}$ pixels in the pulp by age. Microscopic images showing Lef1 expression in odontoblasts in the $(E) 1 \mathrm{M},(F) 4 \mathrm{M}$, and $(G) 6 \mathrm{M}$ groups. $(H)$ Quantification of Lef $1^{\text {+ve }}$ pixels in the pulp by age. (I) GFP ${ }^{+v e}$, Wnt-responsive cells in the maxillary first molar dental pulp of $1 \mathrm{M}$-old mice 5 days after tamoxifen treatment. GFP ${ }^{+v e}$, Wntresponsive cells were examined with $(J)$ 1-month tracing and $(K)$ 3-month tracing. $(L)$ Quantification of $\mathrm{GFP}^{+v e}$, Wnt-responsive cells in the pulp area. Coimmunostaining of apoptosis marker caspase $3(r e d)$ with Wnt-responsive cells (green) in odontoblasts of $(M) 1 \mathrm{M},(N) 4 \mathrm{M}$, and $(O) 6 \mathrm{M}$ mice. Immunostaining for the proliferation marker PCNA in odontoblasts in $(P) 1 \mathrm{M},(Q) 4 \mathrm{M}$, and $(R) 6 \mathrm{M}$ mice. $(S)$ Quantification of $P C N A^{+v e}$ pixels in the pulp by age. Pentachrome staining showing the odontoblasts in the maxillary first molar in $(T) 1 \mathrm{M},(U) 4 \mathrm{M}$, and $(V) 6 \mathrm{M}$ mice. Double-headed arrows indicate the odontoblast 
layer. $d$, dentin; LEF1, lymphoid enhancer binding factor 1; $p$, pulp; PCNA, proliferating cell nuclear antigen. Scale bars $=25 \mu \mathrm{m}$. Data are expressed as the mean \pm standard deviation. ${ }^{*} P<.05 ;{ }^{* *} P<.01 ;{ }^{* * *} P<.0001$

We used a second method to determine if endogenous Wnt signaling declined with age. In 1-month-old mice, cells at the dentin/pulp interface abundantly expressed the Wnt transcription factor lymphoid enhancer-binding factor-1 (Lef1) (Fig. 2E). Lef1 immunostaining was reduced in 4-month-old mice (Fig. $2 F$ ), and by 6 months of age, Lef $1^{\text {tve }}$ cells were no longer detectable in the pulp (Fig. 2G), showing a progressive decline in Wnt signaling in the pulp as a function of age (quantified in Fig. $2 H$ ).

The gradual loss in Wnt-responsive odontoblasts was confirmed using a lineage tracing

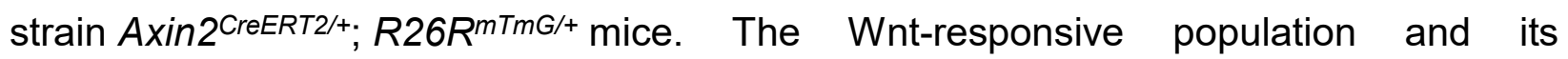
descendants were identifiable by virtue of their GFP expression. In 1-month-old mice, most odontoblasts were GFP ${ }^{+v e}$ (Fig. 2/), indicating that they were responsive to an endogenous Wht signal. In 2-month-old mice, the number of GFP ${ }^{+v e}$ cells had declined significantly (Fig. 2J), indicating that descendants of the initial Wnt-responsive population had been lost. In 4-month-old mice, GFP ${ }^{+v e}$ descendants of the initial Wnt-responsive population had diminished still further (Fig. $2 K$, quantified in Fig. $2 L$ ).

How were the GFP $^{+v e}$ cells lost? Coimmunostaining of GFP and the apoptosis marker caspase 3 was performed at the 1, 4, and 6-month time points. Only the 1-month old mice showed evidence of GFP/caspase 3 coexpression (Fig. 2M); in 4- and 6-month old mice, caspase 3 expression was undetectable (Fig. $2 \mathrm{~N}$ and $\mathrm{O}$ ). Therefore, some reduction in the Wnt-responsive population appeared to be caused by apoptosis. Coupled with the gradual reduction in mitotic activity as shown by proliferating cell nuclear antigen immunostaining (Fig. $2 P-S$ ), it became readily apparent that the density of Wntresponsive cells at the dentin-pulp interface was reduced as a function of age (Fig. $2 T-$ V).

\section{WNT SIGNALING REGULATES THE RATE OF DENTIN SECRETION}

Thus far, data showed a correlation between Wnt signaling and the rate of dentin deposition. To establish a causal relationship between Wnt signaling and the rate of 
dentin deposition, we genetically engineered odontoblasts to always express a stabilized form of the Wnt pathway intermediate, beta-catenin. To achieve this, we used a strain of mice in which Cre was expressed in odontoblasts. Odontoblasts and pulp cells expressed DMP1 (Fig. $3 A$ ), suggesting that the DMP1-Cre strain of mice could serve as a means to activate Wnt signaling in odontoblasts.

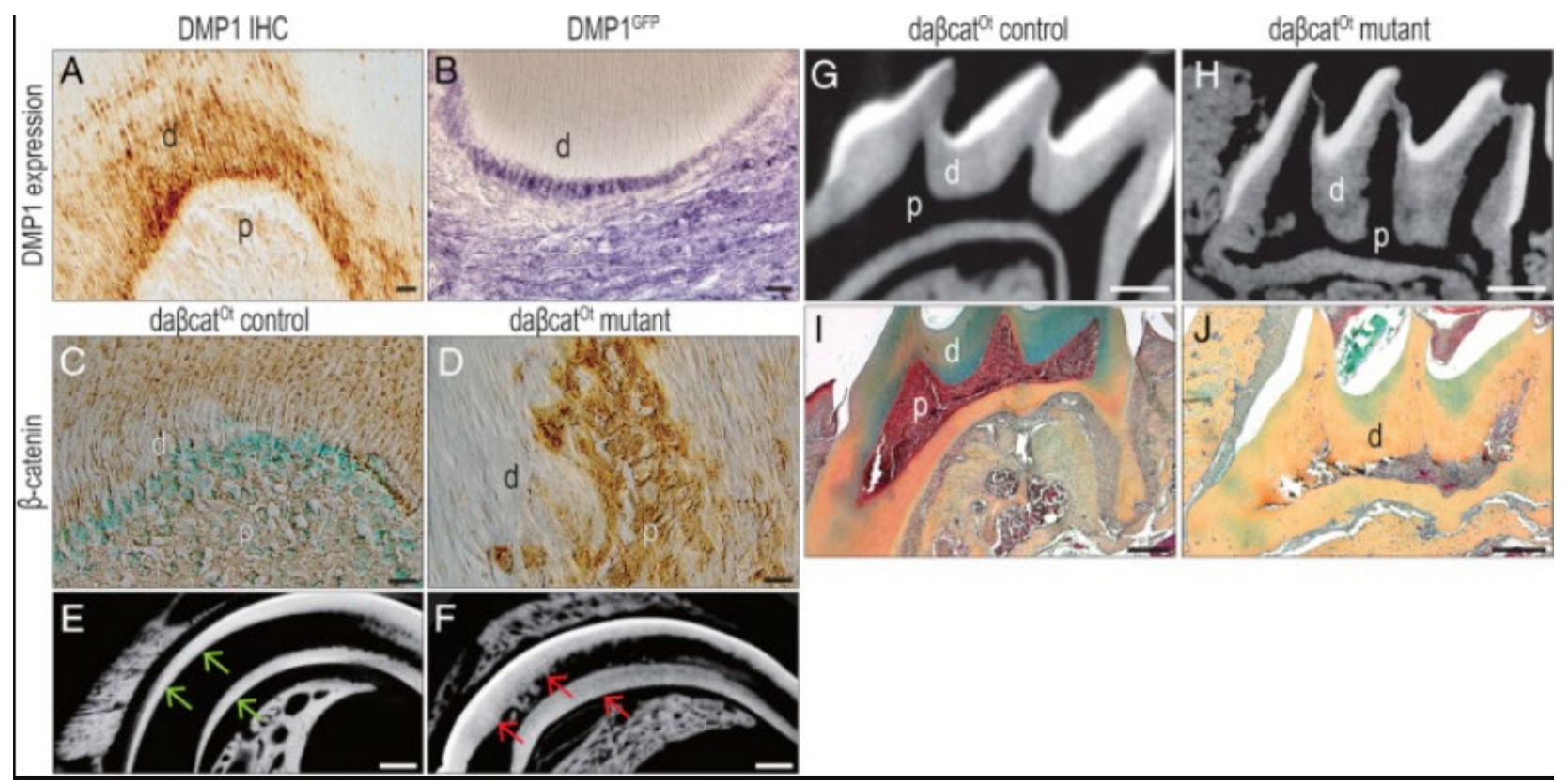

Figure 3. Wnt signaling regulates the rate of dentin secretion. (A) Immunohistochemistry identifies DMP1 expression (brown) in a maxillary first molar. $(B)$ Immunohistochemistry confirmed the GFP expression (purple) in a maxillary first molar in DMP1GFP mice. Immunohistochemistry for beta-catenin (brown) in odontoblasts in $(C)$ control and $(D)$ daßcat ${ }^{\mathrm{Ot}}$ mutant mice (42 days old). The sections were counterstained with fast green. Representative micro-computed tomographic sagittal sectional reconstructed images of an incisor from $(E)$ control and $(F)$ daßcat ${ }^{\mathrm{Ot}}$ mutant mice (42 days old). Representative micro-computed tomogrpahic sagittal sectional reconstructed images of the maxillary first molar from $(G)$ control and $(H)$ daßcat ${ }^{\mathrm{Ot}}$ mutant mice (42 days old). Pentachrome staining of the maxillary first molar from $(I)$ control and $(J)$ daßcat ${ }^{\text {Ot }}$ mutant mice (42 days old). Dentin stains green to yellow, with the more mature dentin staining yellow. $d$, dentin; $p$, pulp. Scale bars $=(A-D) 25 \mu \mathrm{m}$ and $(E-J) 200 \mu \mathrm{m}$. 
We confirmed that DMP1 was expressed in odontoblasts and pulp cells by following the expression of GFP in DMP1GFP reporter mice. In these transgenic mice, GFP is under control of the DMP1 promoter, and as expected, odontoblasts were positively labeled (Fig. $3 B$ ). We then proceeded with crossing DMP1-Cre mice with a strain of mice expressing the stabilized form of beta-catenin. These mice, referred to as daßcatot, exhibited amplified Wnt/beta-catenin signaling in DMP-expressing cells (Fig. $3 C$ and $D^{27}$ ).

Compared with age-matched littermates (Fig. $3 E$ ), significantly more dentin accumulated in daßcat ${ }^{\mathrm{Ot}}$ mutant teeth in both the incisors (Fig. $3 F$ ) and the molars (compare Fig. $3 G$ with $H$ ). The dentin accumulation nearly eliminated the pulp cavity in the crown region (Fig. $3 G$ and $H$ ). Histologic analyses confirmed micro-computed tomographic imaging (compare Fig. $3 /$ with $\mathrm{J}$ ). Cumulatively, these data showed that amplified Wnt signaling in odontoblasts led to a dramatic increase in dentin accumulation.

\section{ACCELERATING DEPOSITION CONVERTS A TUBULAR DENTIN INTO OSTEODENTIN}

The nature of the dentin was examined in daßcat ${ }^{O t}$ mutant mice. Although in control animals the tubular structure of dentin was obvious and the pulp cavity was densely cellular (Fig. 4A), the dentin of daßcat ${ }^{\mathrm{Ot}}$ mutant had no tubular arrangement, and cells were trapped within the mineralized matrix (Fig. $4 B$ ). In controls, aniline blue staining highlighted the ordered nature of the odontoblasts and the tubular dentin (Fig. 4C); in daßcat ${ }^{\text {Ot }}$ mutants, the odontoblasts were disorganized, and the dentin had an osteoidlike appearance (Fig. $4 D$ ). 


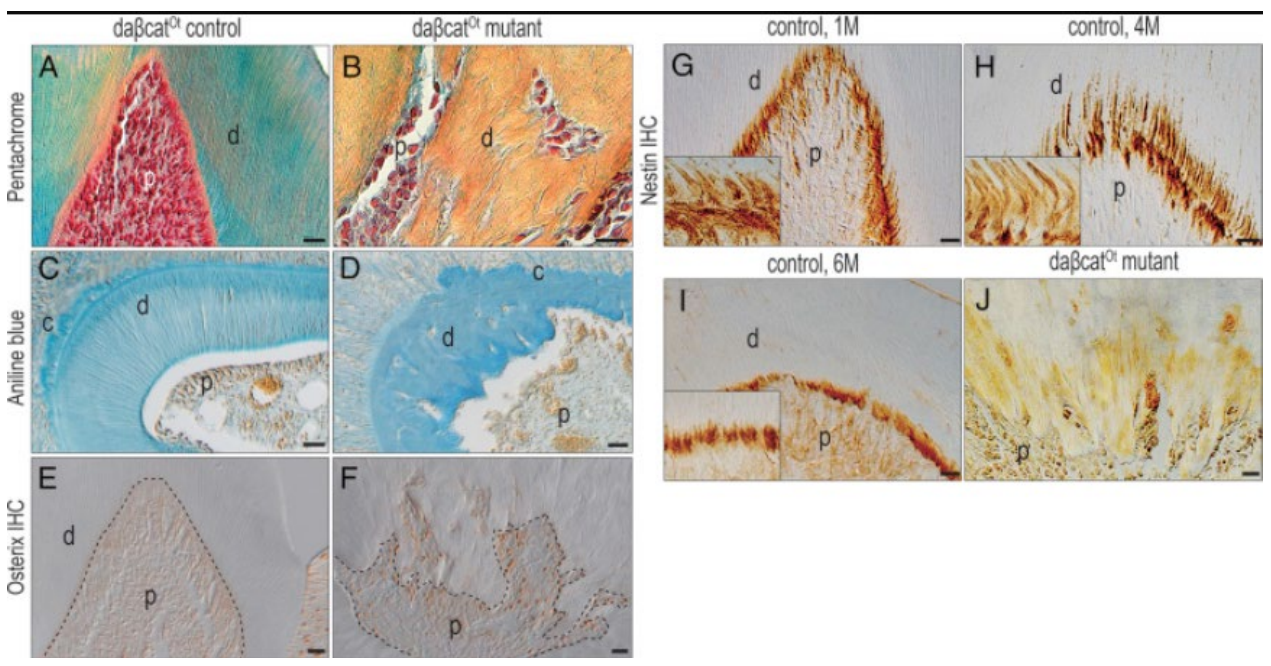

Figure 4. Accelerating deposition converts a tubular dentin into osteodentin. Representative pentachrome staining of a maxillary first molar in $(A)$ control and $(B)$ daßcat ${ }^{O t}$ mutant mice. A representative cross section of aniline blue staining of the maxillary first molar in $(C)$ control and $(D)$ daßcat ${ }^{\circ t}$ mutant mice. Immunostaining of osterix of the maxillary first molar in $(E)$ control and $(F)$ daßcat ${ }^{\mathrm{Ot}}$ mutant mice. Immunostaining of nestin in $(G)$ 1-month $(1 \mathrm{M}),(H)$ 4-month $(4 \mathrm{M})$, and $(I)$ 6-month $(6 \mathrm{M})$ control mice. $(J)$ Immunostaining of nestin in daßcat ${ }^{O t}$ mutant mice. $d$, dentin; $p$, pulp. Scale bar $=25 \mu \mathrm{m}$.

Osterix expression was undetectable in the adult pulp of control mice (Fig. $4 E$ ). In contrast, osterix was strongly expressed in the adult pulp of daßcat ${ }^{\mathrm{Ot}}$ mutant mice (Fig. 4F), indicating the preodontoblasts, instead of odontoblasts, were presented in daßcat ${ }^{\mathrm{Ot}}$ mutant. Nestin is expressed by mature, fully differentiated odontoblasts as shown by analyses of 1-, 4-, and 6-month-old pulps (Fig. 4G-128, 29). In daßcat ${ }^{\mathrm{Ot}}$ mutants, nestin expression was abolished and in its place were only preodontoblasts secreting atubular osteodentin (Fig. 4J). These data supported our hypothesis that aberrantly elevated Wnt signaling triggered osteodentin production by preodontoblasts. 


\section{DISCUSSION}

\section{WNT SIGNALS MAINTAIN DENTIN SECRETION}

Here we provide evidence that the survival of odontoblasts and their continued production of dentin is ensured in part by endogenous Wnt signaling. This interpretation is strongly supported by the literature $\frac{30}{}$. For example, using a loss-of-function approach, Han et al 131 showed that beta-catenin was required for odontoblast differentiation, and in a murine preclinical study, Yoshioka et al $\underline{32}$ showed that Wnt signaling and beta-catenin are both up-regulated in response to subacute pulp trauma. These data and others $\underline{19}, \underline{33}$ firmly establish the $\mathrm{Wnt} /$ beta-catenin pathway as a critical regulator of odontoblast function. We extend these observations by showing that the age-related decline in dentin production is mirrored by a decline in Wnt signaling (Fig. 1) and a diminishment in the population of Wnt-responsive cells in the pulp (Fig. 2).

Not all published data comport with our model. For example, Amri et al $\underline{34}$ showed that rather than activation, inhibition of Wnt/beta-catenin signaling by Msx 2 controls the formation of osteodentin. It is not clear at this time how these data can be reconciled with findings shown here. Others have shown using in vitro analyses that Msx2 enhances Wnt signaling and promotes mineralization $\underline{35}$. Some of these differences may be caused by timing or the duration of the Wnt signal. Indeed, constitutive activation or constitutive repression of the Wnt/beta-catenin pathway can lead to similar outcomes in mineralized tissues.

\section{THE REPAIR RESPONSE OF THE PULP IS ORCHESTRATED BY WNT SIGNALS}

In patients and animal models, the pulp shows an extraordinarily vigorous repair response to trauma. Variously referred to as reactionary, reparative, and tertiary dentin, the mineralized matrix produced in response to injury tends to be atubular and rather than being secreted by fully differentiated odontoblasts, it is produced by preodontoblastic progenitor cells in the pulp $\underline{6}, \underline{36}$. This "backup" system appears to be ideally suited for a relatively quiescent tissue that must survive for an entire lifetime. How this quiescent status is maintained and how it is reversed upon injury are still open for debate. In tissues that do not turn over, adult stem cells exist in a mitotically arrested state with a low 
metabolic demand $\frac{37}{7}$. However, in response to injury, this stem cell pool is capable of proliferating and then differentiating to aid in tissue repair 37 . Applying this theory to the pulp seems reasonable; it is a tissue with a very low turnover rate but fully capable of mounting a robust repair response to trauma. In many tissues, Wnt signals maintain adult stem cells in a quiescent state $\frac{38}{2}$, and we propose the pathway plays a similar role in the adult pulp.

\section{CLINICAL IMPLICATIONS}

If primary odontoblasts respond to trauma and secrete copious amounts of new dentin, then the pulp generally retains its vitality. When that repair response is attenuated with age, the result is typically chronic inflammation followed by pulp necrosis, which necessitates a root canal. The vast majority of endodontic cases begin with subacute, chronic trauma to the pulp (eg, chronic pulpitis that is not adequately repaired by the pulp's natural defense strategy). Our goal is to devise new biologically based strategies to enhance this natural repair response that has become attenuated as a result of aging.

We envision a therapeutic strategy to stimulate the repair potential of an aged pulp by enhancing Wnt signaling via delivery of a liposomal formulation of the WNT protein. We showed the feasibility of such an approach $\frac{15}{}$ with one important caveat. In our studies, the dentin injury was produced in an otherwise healthy tooth. This characteristic does not match with most endodontic pulp cases in which the pulp is inflamed and potentially infected at the time of treatment. Consequently, it will be critically important to test a WNTbased strategy to enhance dentin secretion in a model that replicates this clinical scenario.

\section{ACKNOWLEDGMENTS}

Yuan Zhao and Xue Yuan contributed equally to this study.

The authors thank Ustun Serdar Tulu for his help in micro-computed tomographic analysis and Joseph Grauer for his insight and revision of the manuscript.

Supported by grants from the National Institutes of Health (grant no. R01DE024000-11) to J.A.H. and National Natural Science Foundation of China (grant no. 81500835), 
the Fundamental Research Funds for the Central Universities (grant no. Izujbky-201897), and Longyuan Youth Innovation and Talent Individual Project to Y.Z.

The authors deny any conflicts of interest related to this study.

\section{REFERENCES}

1. Feng, X., \& McDonald, J. M. (2011). Disorders of Bone Remodeling. Annual Review of Pathology: Mechanisms of Disease, 6(1), 121-145. https://doi.org/10.1146/annurevpathol-011110-130203

2. Rachner, T. D., Khosla, S., \& Hofbauer, L. C. (2011). Osteoporosis: Now and the future. The Lancet, 377(9773), 1276-1287. https://doi.org/10.1016/S0140-6736(10)62349-5

3. Gupta, P., Kaur, H., Shankari G.S., M., Jawanda, M. K., \& Sahi, N. (2014). Human Age Estimation from Tooth Cementum and Dentin. Journal of Clinical and Diagnostic Research : JCDR, 8(4), ZC07-ZC10. https://doi.org/10.7860/JCDR/2014/7275.4221

4. Smith, A. J., Cassidy, N., Perry, H., Begue-Kirn, C., Ruch, J. V., \& Lesot, H. (2003). Reactionary dentinogenesis. International Journal of Developmental Biology, 39(1), 273280. https://doi.org/10.1387/ijdb.7626417

5. Tomes, C. S., \& Tomes, J. (1878). II. On the structure and development of vascular dentine. Proceedings of the Royal Society of London, 26(179-184), 43-47. https://doi.org/10.1098/rspl.1877.0007

6. Goldberg, M., Kulkarni, A. B., Young, M., \& Boskey, A. (2011). Dentin: Structure, Composition and Mineralization. Frontiers in Bioscience (Elite Edition), 3, 711-735.

7. Aguiar, M. C., \& Arana-Chavez, V. E. (2007). Ultrastructural and immunocytochemical analyses of osteopontin in reactionary and reparative dentine formed after extrusion of upper rat incisors. Journal of Anatomy, 210(4), 418-427. https://doi.org/10.1111/j.14697580.2007.00708.x

8. Baron, R., \& Rawadi, G. (2007). Wnt signaling and the regulation of bone mass. Current Osteoporosis Reports, 5(2), 73-80. https://doi.org/10.1007/s11914-007-0006-0

9. Krishnan, V., Bryant, H. U., \& MacDougald, O. A. (2006). Regulation of bone mass by Wnt signaling. The Journal of Clinical Investigation, 116(5), 1202-1209. https://doi.org/10.1172/JCl28551 
10.Zhong, Z., Ethen, N. J., \& Williams, B. O. (2014). WNT signaling in bone development and homeostasis. WIREs Developmental Biology, 3(6), 489-500. https://doi.org/10.1002/wdev.159

11. Bodine, P. V. N., \& Komm, B. S. (2006). Wnt signaling and osteoblastogenesis. Reviews in Endocrine and Metabolic Disorders, 7(1), 33-39. https://doi.org/10.1007/s11154-006$\underline{9002-4}$

12. Cui, Y., Niziolek, P. J., MacDonald, B. T., Zylstra, C. R., Alenina, N., Robinson, D. R., Zhong, Z., Matthes, S., Jacobsen, C. M., Conlon, R. A., Brommage, R., Liu, Q., Mseeh, F., Powell, D. R., Yang, Q. M., Zambrowicz, B., Gerrits, H., Gossen, J. A., He, X., ... Robling, A. G. (2011). Lrp5 functions in bone to regulate bone mass. Nature Medicine, 17(6), 684-691. https://doi.org/10.1038/nm.2388

13. Van Wesenbeeck, L., Cleiren, E., Gram, J., Beals, R. K., Bénichou, O., Scopelliti, D., Key, L., Renton, T., Bartels, C., Gong, Y., Warman, M. L., de Vernejoul, M.-C., Bollerslev, J., \& Van Hul, W. (2003). Six Novel Missense Mutations in the LDL Receptor-Related Protein 5 (LRP5) Gene in Different Conditions with an Increased Bone Density. The American Journal of Human Genetics, 72(3), 763-771. https://doi.org/10.1086/368277

14. Costa, A. G., \& Bilezikian, J. P. (2012). Sclerostin: Therapeutic Horizons Based Upon Its Actions. Current Osteoporosis Reports, 10(1), 64-72. https://doi.org/10.1007/s11914$\underline{011-0089-5}$

15.Zhao, Y., Yuan, X., Liu, B., Tulu, U. S., \& Helms, J. A. (2018). Wnt-Responsive Odontoblasts Secrete New Dentin after Superficial Tooth Injury. Journal of Dental Research, 97(9), 1047-1054. https://doi.org/10.1177/0022034518763151

16. Lohi, M., Tucker, A. S., \& Sharpe, P. T. (2010). Expression of Axin2 indicates a role for canonical Wnt signaling in development of the crown and root during pre- and postnatal tooth development. Developmental Dynamics, 239(1), 160-167. https://doi.org/10.1002/dvdy.22047

17. Kim, T. H., Bae, C. H., Lee, J. C., Ko, S. O., Yang, X., Jiang, R., \& Cho, E. S. (2013). ßcatenin is Required in Odontoblasts for Tooth Root Formation. Journal of Dental Research, 92(3), 215-221. https://doi.org/10.1177/0022034512470137

18. Lim, W. H., Liu, B., Cheng, D., Hunter, D. J., Zhong, Z., Ramos, D. M., Williams, B. O., Sharpe, P. T., Bardet, C., Mah, S., \& Helms, J. A. (2014). Wnt Signaling Regulates Pulp 
Volume and Dentin Thickness. Journal of Bone and Mineral Research, 29(4), 892-901. https://doi.org/10.1002/jbmr.2088

19. Hunter, D. J., Bardet, C., Mouraret, S., Liu, B., Singh, G., Sadoine, J., Dhamdhere, G., Smith, A., Tran, X. V., Joy, A., Rooker, S., Suzuki, S., Vuorinen, A., Miettinen, S., Chaussain, C., \& Helms, J. A. (2015). Wnt Acts as a Prosurvival Signal to Enhance Dentin Regeneration. Journal of Bone and Mineral Research, 30(7), 1150-1159. https://doi.org/10.1002/jbmr.2444

20. Ishimoto, K., Hayano, S., Yanagita, T., Kurosaka, H., Kawanabe, N., Itoh, S., Ono, M., Kuboki, T., Kamioka, H., \& Yamashiro, T. (2015). Topical Application of Lithium Chloride on the Pulp Induces Dentin Regeneration. PLOS ONE, 10(3), e0121938. https://doi.org/10.1371/journal.pone.0121938

21. Lustig, B., Jerchow, B., Sachs, M., Weiler, S., Pietsch, T., Karsten, U., Wetering, M. van de, Clevers, H., Schlag, P. M., Birchmeier, W., \& Behrens, J. (2002). Negative Feedback Loop of Wnt Signaling through Upregulation of Conductin/Axin2 in Colorectal and Liver Tumors. Molecular and Cellular Biology, 22(4), 1184-1193. https://doi.org/10.1128/MCB.22.4.1184-1193.2002

22. Lu, Y., Xie, Y., Zhang, S., Dusevich, V., Bonewald, L. F., \& Feng, J. Q. (2007). DMP1targeted Cre Expression in Odontoblasts and Osteocytes. Journal of Dental Research, 86(4), 320-325. https://doi.org/10.1177/154405910708600404

23. Rauch, D. A., Hurchla, M. A., Harding, J. C., Deng, H., Shea, L. K., Eagleton, M. C., Niewiesk, S., Lairmore, M. D., Piwnica-Worms, D., Rosol, T. J., Weber, J. D., Ratner, L., \& Weilbaecher, K. N. (2010). The ARF Tumor Suppressor Regulates Bone Remodeling and Osteosarcoma Development in Mice. PLOS ONE, 5(12), e15755. https://doi.org/10.1371/journal.pone.0015755

24.Xu, Q., Yuan, X., Zhang, X., Chen, J., Shi, Y., Brunski, J. B., \& Helms, J. A. (2019). Mechanoadaptive Responses in the Periodontium Are Coordinated by Wnt. Journal of Dental Research, 98(6), 689-697. https://doi.org/10.1177/0022034519839438

25. Minear, S., Leucht, P., Jiang, J., Liu, B., Zeng, A., Fuerer, C., Nusse, R., \& Helms, J. A. (2010). Wnt Proteins Promote Bone Regeneration. Science Translational Medicine, 2(29), 29ra30-29ra30. https://doi.org/10.1126/scitranslmed.3000231 
26. Doello, K. (2014). A New Pentachrome Method for the Simultaneous Staining of Collagen and Sulfated Mucopolysaccharides. The Yale Journal of Biology and Medicine, 87(3), 341-347.

27.Tu, X., Delgado-Calle, J., Condon, K. W., Maycas, M., Zhang, H., Carlesso, N., Taketo, M. M., Burr, D. B., Plotkin, L. I., \& Bellido, T. (2015). Osteocytes mediate the anabolic actions of canonical $\mathrm{Wnt} / \beta$-catenin signaling in bone. Proceedings of the National Academy of Sciences, 112(5), E478-E486. https://doi.org/10.1073/pnas.1409857112

28. Fujita, S., Hideshima, K., \& Ikeda, T. (2006). Nestin expression in odontoblasts and odontogenic ectomesenchymal tissue of odontogenic tumours. Journal of Clinical Pathology, 59(3), 240-245. https://doi.org/10.1136/jcp.2004.025403

29. Miyazaki, T., Kanatani, N., Rokutanda, S., Yoshida, C., Toyosawa, S., Nakamura, R., Takada, S., \& Komori, T. (2008). Inhibition of the terminal differentiation of odontoblasts and their transdifferentiation into osteoblasts in $<\mid>$ Runx $2</ \mid>$ transgenic mice. Archives of Histology and Cytology, 71(2), 131-146. https://doi.org/10.1679/aohc.71.131

30. Rosa, W. L. O. da, Piva, E., \& Silva, A. F. da. (2018). Disclosing the physiology of pulp tissue for vital pulp therapy. International Endodontic Journal, 51(8), 829-846. https://doi.org/10.1111/iej.12906

31. Han, N., Zheng, Y., Li, R., Li, X., Zhou, M., Niu, Y., \& Zhang, Q. (2014). ß-Catenin Enhances Odontoblastic Differentiation of Dental Pulp Cells through Activation of Runx2. PLOS ONE, 9(2), e88890. https://doi.org/10.1371/journal.pone.0088890

32. Yoshioka, S., Takahashi, Y., Abe, M., Michikami, I., Imazato, S., Wakisaka, S., Hayashi, M., \& Ebisu, S. (2013). Activation of the $\mathrm{Wnt} / \mathrm{\beta}$-catenin pathway and tissue inhibitor of metalloprotease 1 during tertiary dentinogenesis. The Journal of Biochemistry, 153(1), 43-50. https://doi.org/10.1093/jb/mvs117

33. Aurrekoetxea, M., Irastorza, I., García-Gallastegui, P., Jiménez-Rojo, L., Nakamura, T., Yamada, Y., Ibarretxe, G., \& Unda, F. J. (2016). Wnt/ $\beta$-Catenin Regulates the Activity of Epiprofin/Sp6, SHH, FGF, and BMP to Coordinate the Stages of Odontogenesis. Frontiers in Cell and Developmental Biology, 4. https://doi.org/10.3389/fcell.2016.00025 34. Amri, N., Djolé, S. X., Petit, S., Babajko, S., Coudert, A. E., Castaneda, B., Simon, S., \& Berdal, A. (2016). Distorted Patterns of Dentinogenesis and Eruption in Msx2 Null 
Mutants: Involvement of Sost/Sclerostin. The American Journal of Pathology, 186(10), 2577-2587. https://doi.org/10.1016/j.ajpath.2016.06.013

35. Cheng, S.-L., Shao, J.-S., Cai, J., Sierra, O. L., \& Towler, D. A. (2008). Msx2 Exerts Bone Anabolism via Canonical Wnt Signaling. Journal of Biological Chemistry, 283(29), 2050520522. https://doi.org/10.1074/jbc.M800851200

36. Simon, S., Cooper, P., Smith, A., Picard, B., Ifi, C. N., \& Berdal, A. (2008). Evaluation of a new laboratory model for pulp healing: Preliminary study. International Endodontic Journal, 41(9), 781-790. https://doi.org/10.1111/j.1365-2591.2008.01433.x

37. Cheung, T. H., \& Rando, T. A. (2013). Molecular regulation of stem cell quiescence. Nature Reviews Molecular Cell Biology, 14(6), 329-340. https://doi.org/10.1038/nrm3591 38. Li, L., \& Clevers, H. (2010). Coexistence of Quiescent and Active Adult Stem Cells in Mammals. Science, 327(5965), 542-545. https://doi.org/10.1126/science.1180794

\section{SUPPLEMENTAL METHODS AND MATERIALS}

\section{ANIMALS}

Axin2 $2^{\text {LacZ/+ }}(\# 11809809)$ and Axin2 ${ }^{\text {CreERT2/+; }}$ R26R $^{m T m G /+}(\# 018867$ and \#007576) mice were obtained from Jackson Labs (Bar Harbor, ME). To induce Cre expression in Axin2 $2^{\mathrm{CreERT2/+}}$; $R 26 R^{m T m G /+}$ mice, tamoxifen (4 mg/25 g body weight) was delivered intraperitoneally for 3 consecutive days; animals were then sacrificed at the indicated time points. In this strain, delivery of tamoxifen instigates a recombination event wherein cells that are responsive to endogenous Wnt signaling start to express green fluorescent protein (GFP). Subsequently, any descendants arising from this initial population of Wntresponsive cells are also labeled with GFP. This strategy allowed us to unambiguously determine whether Wnt-responsive cells in the dentin-pulp complex declined with age.

Daßcat ${ }^{\mathrm{Ot}}$ mice were generated by crossing dentin matrix acidic phosphoprotein 1 (DMP1)-8kb-Cre mice with Catnb ${ }^{\text {lox(ex3) }}$ mice in which LoxP sites flank exon 3 that encodes for beta-catenin degradation 1,2 . DMP1-8kb-Cre ${ }^{+/-}$mice were crossed with Catnb ${ }^{10 x(e x 3) / / o x(e x 3)}$ mice to generate Catnb ${ }^{\text {lox(ex3)/+; }}$ DMP1-8kb-Cre ${ }^{+/-}$(daßcat ${ }^{\mathrm{Ot}}$ mutant

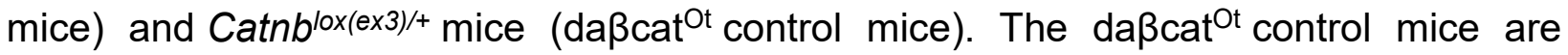
indistinguishable from the wild-type C57BL/6 mice and used as littermate controls in the 
current study. Mice expressing GFP in osteocytes $(D M P 1 G F P) \underline{3}, \underline{4}$ were also used in this study.

\section{X-gal Staining}

To detect beta-galactosidase activity, sections were fixed with $0.2 \%$ glutaraldehyde/phosphate-buffered saline (PBS) for 15 minutes and then washed 3 times with wash buffer containing $0.005 \%$ Nonidet P-40 (Sigma-Aldrich, St. Louis, MO), 0.01\% sodium deoxycholate, and $2 \mathrm{mmol} / \mathrm{L} \mathrm{MgCl}_{2} / \mathrm{PBS}$. Tissue sections were stained overnight at $37^{\circ} \mathrm{C}$ in a staining solution containing $5 \mathrm{mmol} / \mathrm{L}$ potassium ferricyanide, $5 \mathrm{mmol} / \mathrm{L}$ potassium ferrocyanide, $2 \mathrm{mmol} / \mathrm{L} \mathrm{MgCl}$, and $1 \mathrm{mg} / \mathrm{mL} \mathrm{X-gal} \mathrm{(Thermo} \mathrm{Fisher} \mathrm{Scientific,}$ Waltham, MA). Sections were rinsed 2 times in PBS, dehydrated in a graded ethanol series, and cleared in CitriSolv (Fisher Scientific, Pittsburgh, PA) and then mounted with Permount (Fisher Scientific) $\underline{5}, \underline{6}$.

\section{Micro-computed Tomographic Analyses}

Micro-computed tomographic imaging was performed using a SkyScan 1176 scanner (SkyScan, Bruker, Belgium) at a 5- $\mu \mathrm{m}$ resolution. Scanning was done at $45 \mathrm{kV}, 556 \mathrm{~mA}$. Samples were reconstructed and segmented with ScanIP (Synopsys, Mountain View, CA). CT Analyzer software (version 1.02, SkyScan) was used for morphometric quantification.

\section{Immunohistochemistry}

Primary antibodies and their dilutions are as follows: anti-osterix (ab22552; Abcam, Cambridge, UK), anti-CTNNB1 (â-catenin) antibody (BD Biosciences, East Rutherford, NJ), antinestin (ab6142, Abcam), anti-Lef1 (2230S; Cell Signaling Technology, Danvers, MA), anti-GFP (2956, Cell Signaling Technology), and anti-DMP1 (ab103203, Abcam). In all cases, the negative controls were performed at the same time using PBS to substitute primary antibody. Secondary antibodies are biotinylated goat antirabbit immunoglobulin G antibody (BA-1000; Vector Lab, Burlingame, CA) and biotinylated horse antimouse immunoglobulin $\mathrm{G}$ antibody (BA-2000, Vector Lab). The staining was visualized using the ABC peroxidase standard staining kit (32020, Thermo Fisher Scientific) and the DAB peroxidase substrate kit (SK4100, Vector Lab). For GFP staining, nickel solution was 
added to the DAB substrate to enhance the signaling; therefore, the GFP ${ }^{+v e}$ cells were dark purple. For â-catenin staining, fast green was used for counterstaining. Tissue sections were photographed using a digital imaging system (Leica, Wetzlar, Germany).

\section{Histomorphometry}

Histomorphometric measurements were performed to measure the areas of dentin and pulp. From 4 separate time points, 3 mice were analyzed, and from each mouse, 6 tissue sections were chosen for analysis. The dentin, the pulp, and the dentin + pulp areas were calculated using ImageJ (National Institutes of Health, Bethesda, MD) on each tissue section. The area of interest was specified as either the dentin or the pulp, and this value was then divided by the total area occupied by dentin + pulp.

\section{REFERENCES}

Tu, X., Delgado-Calle, J., Condon, K. W., Maycas, M., Zhang, H., Carlesso, N., Taketo, M. M., Burr, D. B., Plotkin, L. I., \& Bellido, T. (2015). Osteocytes mediate the anabolic actions of canonical Wnt/ß-catenin signaling in bone. Proceedings of the National Academy of Sciences, 112(5), E478-E486. https://doi.org/10.1073/pnas.1409857112

Wu, Y., Yuan, X., Perez, K. C., Hyman, S., Wang, L., Pellegrini, G., Salmon, B., Bellido, T., \& Helms, J. A. (2019). Aberrantly elevated Wnt signaling is responsible for cementum overgrowth and dental ankylosis. Bone, 122, 176-183. https://doi.org/10.1016/j.bone.2018.10.023

Kalajzic, I., Braut, A., Guo, D., Jiang, X., Kronenberg, M. S., Mina, M., Harris, M. A., Harris, S. E., \& Rowe, D. W. (2004). Dentin matrix protein 1 expression during osteoblastic differentiation, generation of an osteocyte GFP-transgene. Bone, 35(1), 74-82. https://doi.org/10.1016/j.bone.2004.03.006

Ben-awadh, A. N., Delgado-Calle, J., Tu, X., Kuhlenschmidt, K., Allen, M. R., Plotkin, L. I., \& Bellido, T. (2014). Parathyroid Hormone Receptor Signaling Induces Bone Resorption in the Adult Skeleton by Directly Regulating the RANKL Gene in Osteocytes. Endocrinology, 155(8), 2797-2809. https://doi.org/10.1210/en.2014-1046 
Kim, J.-B., Leucht, P., Lam, K., Luppen, C., Berge, D. T., Nusse, R., \& Helms, J. A. (2007). Bone Regeneration Is Regulated by Wnt Signaling. Journal of Bone and Mineral Research, 22(12), 1913-1923. https://doi.org/10.1359/jbmr.070802

Chai, Y., Jiang, X., Ito, Y., Bringas, P., Han, J., Rowitch, D. H., Soriano, P., McMahon, A. P., \& Sucov, H. M. (2000). Fate of the mammalian cranial neural crest during tooth and mandibular morphogenesis. Development, 127(8), 1671-1679. 